\title{
Forward with Osmosis: Emerging Applications for Greater Sustainability
}

\author{
Laura A. Hoover, William A. Phillip, Alberto Tiraferri, Ngai Yin Yip, and Menachem Elimelech* \\ Department of Chemical and Environmental Engineering, Yale University, New Haven, Connecticut 06520-8286, United States
}

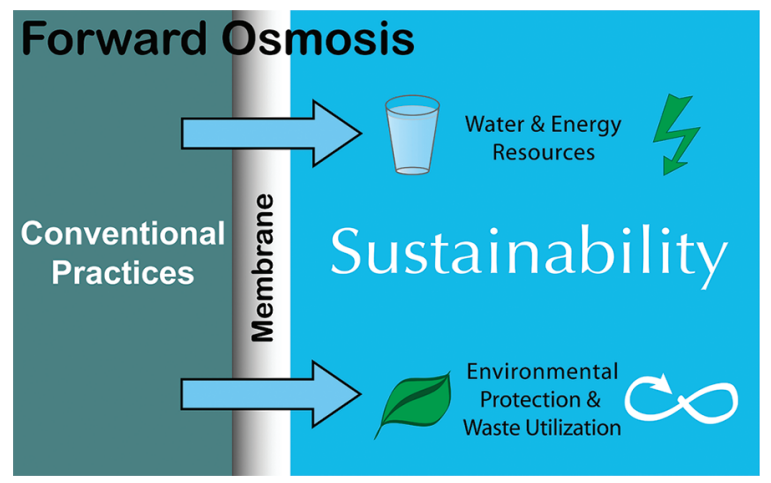

W ater and energy shortages have motivated the development and deployment of a diverse suite of technologies to support our growth beyond the traditional limitations of natural resources. These technologies are diverse not only with respect to method and use, but also in the anticipated consequences of their operation. Our ability to desalinate billions of gallons of seawater daily to satisfy a global water demand that exceeds accessible freshwater resources can be deemed a technological triumph. However, we also recognize that long-term solutions to energy and water shortages cannot rely on provision of one through intense consumption of the other; the vast amount of energy used daily in desalination for potable water production must also be conserved.

Methods that conserve or generate water and energy in a nonpolluting and nonresource-exhausting manner are more capable of sustaining us. Utilizing wastes and abundant, low value resources as inputs for these processes also benefits us in the long term. The "engineered osmosis" processes of forward osmosis (FO) and pressure retarded osmosis have recently received increased attention as technologies that could potentially fulfill these criteria.

In FO, a water-permeable and salt-rejecting membrane is placed between two solutions of different osmotic pressures. These solutions can be natural resources, waste streams, or high purity solutions. Osmosis drives water to permeate through the membrane from the less concentrated "feed solution" to the more concentrated "draw solution". If FO is being employed to extract water from a resource, that resource acts as the feed solution, and it is paired with a draw solution of higher osmotic pressure. Engineered draw solutions are composed of pure water and specifically selected draw solutes. After extracting water from the feed solution, the engineered draw solution is separated into two streams: a concentrated draw solution, which is recycled to the membrane to facilitate continuous FO operation, and freshwater, which is the desired product. Draw solution regeneration can be an energy-intensive step in an otherwise lowenergy process. ${ }^{1}$
However, FO does not require draw solution regeneration in all cases. If a draw solute is used that adds value to the extracted water, the diluted draw solution can be used as is, and new draw solutes can be introduced to the system to create additional product. This is the case in commercially available personal hydration packs, which use a sugar-and-nutrient draw solution to provide energy-boosting drinks from natural waters. ${ }^{2}$ Alternatively, when concentration of the feed solution is the goal, an abundant and low value draw solution, such as seawater, can be used in a once-through fashion. ${ }^{2,3}$

Avoiding draw solution regeneration can bypass a significant energy cost in FO technology implementation. Several emerging applications do just that while performing processes that enhance sustainability at the water-energy nexus. Herein, we highlight five regeneration-free FO applications under development that could benefit society by increasing energy production or efficiency, preventing pollution, utilizing waste, or relieving agriculture associated water stress (Table 1). For each, we will discuss the concept, expected benefits, and anticipated barriers or limitations. In doing so, we hope to motivate academic research, commercial implementation, and discussion of these and other potential uses of forward osmosis.

\section{OSMOTIC DILUTION FOR ENERGY CONSERVATION}

A surging world population, fixed freshwater resources, and limits to water conservation and reclamation make the inclusion of seawater desalination in long-term water production strategies inevitable. Desalination provides needed water, but it also requires a great deal of energy and can adversely impact the environment. The question, then, is how to make desalination as sustainable as possible. FO can help alleviate both energy costs, discussed here, and environmental concerns, discussed in the subsequent section.

The most energy efficient technology for desalination is reverse osmosis, in which a hydraulic pressure, much greater than the osmotic pressure of the saline feedwater, is applied to drive water across a salt-rejecting membrane to produce freshwater. Though great gains in the energy efficiency of reverse osmosis technology have been made over the past few decades, ${ }^{4}$ seawater desalination is an inherently energy-intensive process, and future gains in energy efficiency will be limited. ${ }^{5,6}$ Energy costs contribute as much as $75 \%$ of the operating costs of RO desalination plants. ${ }^{4,7}$ Innovations that reduce energy consumption will strengthen the suitability of reverse osmosis for addressing long-term drinking water needs.

Published: October 26, 2011 
Table 1. Potential Positive Impacts of the Highlighted Technologies on Sustainability at the Water-Energy Nexus

\begin{tabular}{|c|c|c|c|c|}
\hline application of forward osmosis & water & energy & waste utilization & environmental protection \\
\hline $\begin{array}{l}\text { dilution of input stream } \\
\text { to reverse osmosis (RO) } \\
\text { desalination plants }\end{array}$ & $\begin{array}{l}\text { increases pool } \\
\text { of available } \\
\text { water resources. }\end{array}$ & $\begin{array}{l}\text { reduces } \mathrm{RO} \\
\text { operating pressure. }\end{array}$ & $\begin{array}{l}\text { reclaims impaired water } \\
\text { for potable use. }\end{array}$ & \\
\hline $\begin{array}{l}\text { dilution of desalination } \\
\text { plant brine }\end{array}$ & & $\begin{array}{l}\text { provides low-energy } \\
\text { concentration for } \\
\text { chosen feed solution. }\end{array}$ & $\begin{array}{l}\text { usefully employs } \\
\text { impaired water. }\end{array}$ & $\begin{array}{l}\text { dilutes brine and enhances its } \\
\text { dispersion to reduce } \\
\text { harm to marine life. }\end{array}$ \\
\hline $\begin{array}{l}\text { osmotic cleaning of fouled } \\
\text { reverse osmosis membranes }\end{array}$ & & $\begin{array}{l}\text { reduces } \mathrm{RO} \\
\quad \text { operating pressure. }\end{array}$ & & $\begin{array}{l}\text { replaces use of hazardous } \\
\text { cleaning chemicals. }\end{array}$ \\
\hline $\begin{array}{l}\text { cultivation and broth } \\
\text { dewatering for production } \\
\text { of algae biofuels }\end{array}$ & $\begin{array}{l}\text { reduces use of } \\
\text { freshwater in biofuel } \\
\text { algae cultivation. }\end{array}$ & $\begin{array}{l}\text { participates in } \\
\text { fuel production. } \\
\text { reduces energy } \\
\text { used to dewater broth. }\end{array}$ & $\begin{array}{l}\text { uses wastewater nutrients } \\
\text { to cultivate a source } \\
\text { of biofuels. }\end{array}$ & $\begin{array}{l}\text { supports the production of } \\
\text { alternatives to traditional } \\
\text { fuels without increasing } \\
\text { land use. }\end{array}$ \\
\hline $\begin{array}{l}\text { use of brackish water for irrigation } \\
\text { of crops with fertilizer }\end{array}$ & $\begin{array}{l}\text { uses brackish water } \\
\text { to replace or supplement } \\
\text { freshwater use. }\end{array}$ & $\begin{array}{l}\text { reduces energy cost } \\
\text { of desalinating brackish } \\
\text { water for irrigation. }\end{array}$ & & $\begin{array}{l}\text { enables use of local } \\
\text { brackish water resources. }\end{array}$ \\
\hline
\end{tabular}

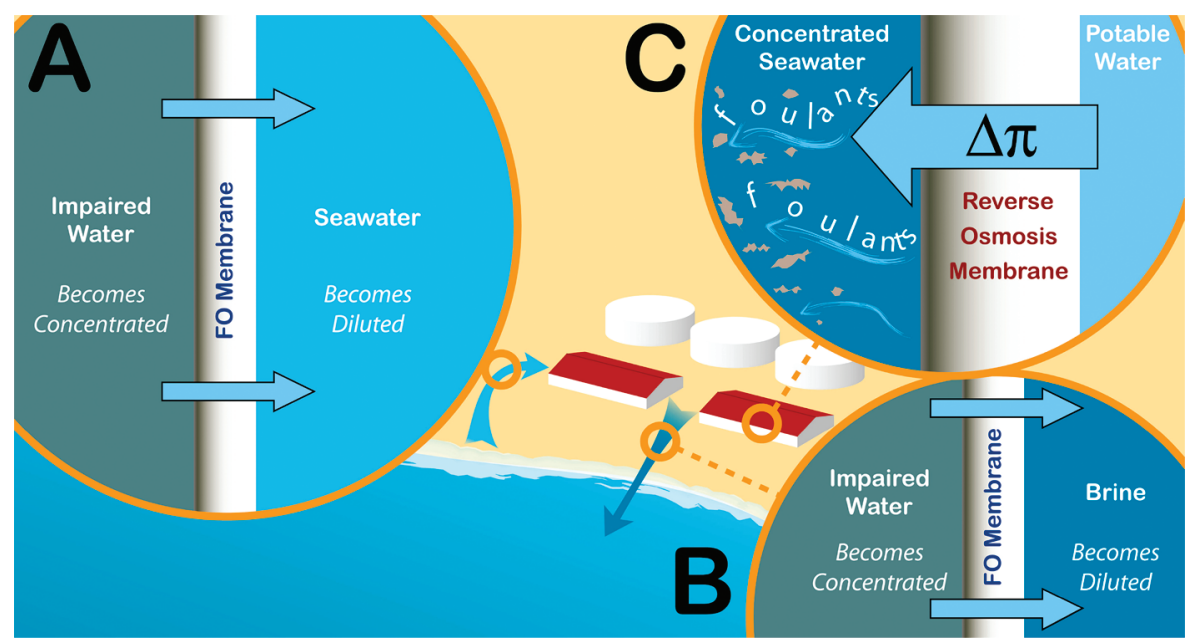

Figure 1. Desalination plant showing three locations where forward osmosis (FO) can be applied to increase sustainability (counter-clockwise): (A) upstream dilution of seawater feed stream to reduce energy consumption; (B) downstream dilution of concentrated brine before discharge to the marine environment; and $(\mathrm{C})$ osmotic backwashing of reverse osmosis membranes to restore membrane performance.

Reverse osmosis would require significantly less energy to desalinate diluted seawater than it does for full strength seawater because dilution decreases the osmotic pressure that must be overcome with applied hydraulic pressure. ${ }^{3,8}$ The amount of energy used in reverse osmosis desalination depends on several additional factors, including the water recovery (i.e., how much of the water in the feed stream is extracted as freshwater). ${ }^{9}$ But even without detailed calculations, one can see that less saline feed streams require less energy by comparing typical energy demands for desalination between brackish water and seawater. Energy usage at reverse osmosis desalination plants ranges from 3 to $7 \mathrm{kWh} / \mathrm{m}^{3}$ for seawater and from 0.5 to $3 \mathrm{kWh} / \mathrm{m}^{3}$ for brackish water, even while brackish water plants operate at much higher recoveries, ${ }^{4}$ which require more energy.

Ideally, water used to dilute the seawater feed stream upstream of the reverse osmosis modules would come from a source that has little alternative use, for example, wastewater effluent or other impaired water. ${ }^{3}$ Such streams cannot be directly mixed into the seawater, as this would introduce additional contaminants and membrane foulants into the feed stream, compromising process efficacy. Direct use of these sources, particularly wastewater, for production of potable water also faces the significant challenge of negative public perception. ${ }^{3}$

FO can safely and efficiently enable the use of impaired water to dilute the seawater entering a reverse osmosis desalination plant (Figure 1A). A low salinity wastewater, or other source, is separated by a selective FO membrane from seawater, which acts as the draw solution and extracts freshwater from the impaired source without incurring the associated contaminants. FO membranes, like reverse osmosis membranes, completely reject pathogens and large molecules, ${ }^{3,8}$ and pairing $\mathrm{FO}$ with reverse osmosis contributes an additional degree of safety for the use of impaired water. Another benefit is that membrane fouling is less problematic for FO than for pressure-driven membrane processes. $^{10}$

Osmotic dilution of seawater feed streams uses impaired water to reduce the energy demand of reverse osmosis desalination. Though this approach offers multibarrier protection of drinking 
water, the challenges associated with societal acceptance of the reclamation of impaired water for potable use may still apply. Education of the public on the benefits and quality of this system can encourage its acceptance. Successful implementation will also require colocation of a source of diluting water with the desalination plant.

\section{- OSMOSIS ENGINEERED FOR PROTECTION OF THE ENVIRONMENT}

Osmosis can be applied elsewhere within desalination plants to reduce the negative impacts of desalination plant discharges on the environment. Greater protection of the environment is particularly needed if the discharge system cannot be constructed at a location where hydrodynamic conditions favor mixing and dispersion. At both membrane-based and thermal desalination installations, FO can be used to dilute concentrated brine before it is discharged into the environment (Figure 1B). Osmotic backwashing can replace harsh chemicals as the primary method of cleaning fouled reverse osmosis membranes (Figure 1C). To explain how these techniques can improve the sustainability of desalination, we first examine the problems to be addressed.

A primary environmental concern for desalination is the difference in salinity and temperature between the discharged brine and the surrounding natural waters receiving the discharge. Whether the desalination plant is based on thermal or membrane processes, the production of freshwater from the saline feed source necessitates the return of more concentrated feedwater to the environment. The high salinity brine discharged by thermal desalination plants will also have an elevated temperature. Aquatic organisms have some ability to adjust to slight changes in salinity and temperature, but significant and sustained changes can devastate species populations at many different levels within ecosystems. ${ }^{11}$ Furthermore, these salinity and temperature differences create density differences between receiving water and discharged brine. Density differences prevent the brine from mixing with and being broadly dispersed-and thus, diluted-by the surrounding water. ${ }^{11}$ The problems associated with brine disposal are thus focused more strongly in the immediate vicinity of the discharge.

In addition to salinity and temperature stresses, flora and fauna at discharge sites face exposure to the diverse fleet of cleaning and pretreatment chemicals that are used to maintain the performance of the desalination plant. Though the concentrations of these chemicals will be low, organisms may be more vulnerable to harm by them because of synergistic effects with temperature and salinity stress. ${ }^{11}$

Osmotic dilution of the brine could mitigate these environmental impacts. As with dilution of seawater feed streams to reverse osmosis plants, a feed solution of lower salinity can be selected to provide diluting water to the brine through an FO membrane (Figure 1B). Because this diluting water will not contribute to the potable water supply, more flexibility exists in feed solution selection. Energy savings for a partner process could be realized if desalination plant brine was diluted through FO by a feed solution that requires concentrating, such as anaerobic digester centrate. ${ }^{2,12}$ To ensure that an environmental benefit is still created by osmotic dilution of the brine, the FO membrane used must be stable in the selected feed solution and must be able to reject all feed solution constituents of environmental concern. The source of the feed solution should also be colocated with the desalination plant, as is true for osmotic dilution of the feed stream to reverse osmosis plants.
Decreasing the salinity and temperature differences between brine and receiving water will enhance natural dispersion of the discharged brine plume, magnifying the initial dilution of salt, temperature differences, and chemicals. Many environmental threats can be mitigated by diluting these chemicals. Biocides, including chlorine and its associated disinfection byproducts, are used to pretreat water for thermal desalination and can harm organisms in the ecosystem surrounding the discharge location. ${ }^{11}$ Thermal desalination plants leach heavy metals, especially copper, and corrosion inhibitors. ${ }^{11}$ Reverse osmosis desalination plants use coagulants to pretreat feedwater, and the water used to back-flush this portion of the plant can have high turbidity. The release of this water decreases light penetration, ${ }^{11}$ and harm to the whole food chain can result. Several different types of chemicals are also used to clean fouled reverse osmosis membranes.

Osmotic backwashing of the membranes used in reverse osmosis desalination can reduce the use and discharge of these membrane cleaning chemicals. Both biological and chemical foulants accumulate on the membrane surface during normal operation. This layer of foulants adds resistance to transport across the membrane, causing water flux and plant efficiency to decline. The harsh chemicals used to reverse this effect include metal chelating agents (such as EDTA), detergents (such as SDS), biocides, acids and bases, and scale inhibitors. Antiscalants, which are also used in thermal desalination plants, can cause eutrophication or may change the distribution of divalent metals in the discharge environment. ${ }^{11}$ The discharge of extreme $\mathrm{pH}$ solutions, detergents, and oxidants used to clean membranes can disrupt aquatic ecosystems.

The concept of osmotic backwashing is relatively simple (Figure 1C). To backwash the membrane, one must reverse the dominance of the hydraulic pressure gradient, which favors permeation of water from seawater into the desalinated water side of the membrane, over the osmotic pressure gradient, which favors water flux in the opposite direction. This can be accomplished in one of two ways. Either the applied hydraulic pressure can be reduced, or the pressure can be maintained and a highly concentrated brine pulse can be introduced into the seawater side of the RO membrane. ${ }^{13}$

In addition to reducing chemical use and discharge, adoption of osmotic backwashing to remove foulants may reduce energy consumption. The harsh chemical cleaning protocols typically used require reverse osmosis train shut-down and can decrease membrane lifetime, ${ }^{14}$ and this type of treatment can be performed only a few times each year. Between cleanings, foulants continually accumulate on the membrane surface, increasing the resistance to water permeation and requiring the applied hydraulic pressure to be increased in order to maintain a constant water flux. Operating at a higher pressure increases the energy consumption. Because osmotic backwashing involves relatively little chemical stress on the membrane or disruption to operation, ${ }^{14}$ it can be performed frequently. This may suppress the buildup of the fouling layer, require smaller pressure increases to maintain constant flux, and ultimately reduce the consumption of energy.

Experimental investigations and modeling have demonstrated fast, effective removal of foulants with osmotic backwashing ${ }^{13,15,16}$ and these findings justify further exploration. Studies involving more complex, realistic fouling conditions could elucidate the mechanisms by which osmotic backwashing removes foulants. This knowledge would aid researchers and industry in identifying the most promising uses of osmotic 


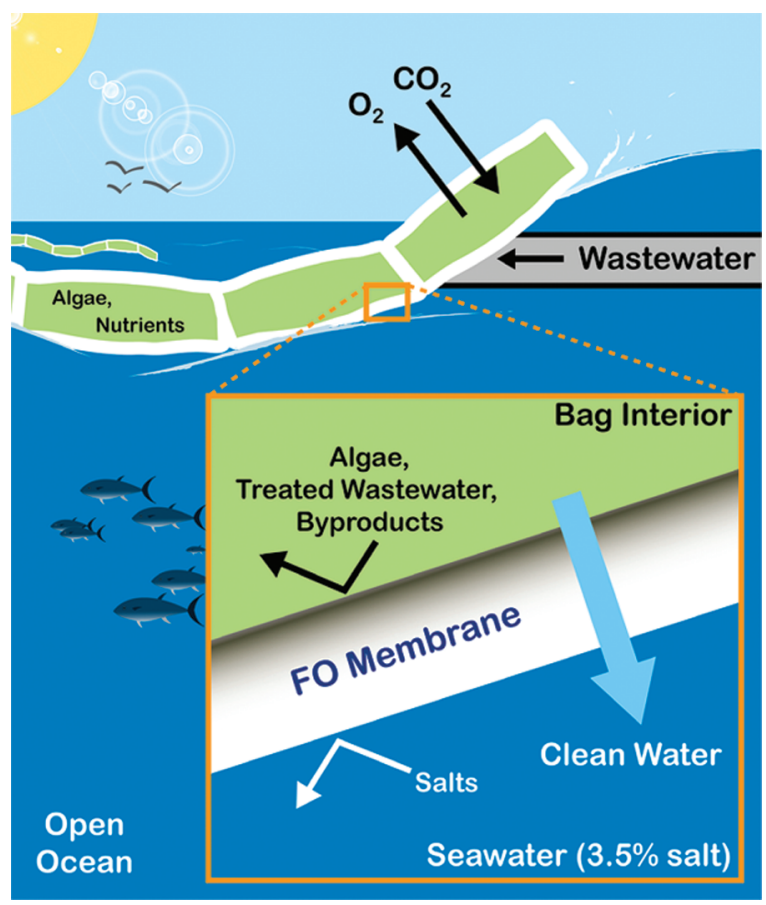

Figure 2. Schematic of the Offshore Membrane Enclosure for Growing Algae (OMEGA) system. Inset shows the permeation through and rejection by the forward osmosis (FO) membrane in contact with the seawater. The top of the enclosure, which is in contact with the atmosphere, contains specialized membranes that allow the passage of sunlight and the exchange of $\mathrm{CO}_{2} / \mathrm{O}_{2}$ to facilitate algae photosynthesis.

backwashing in addition to those aspects that require fuller development.

\section{MEMBRANES AT SEA: FUEL FROM WASTE}

Biofuels are one of the most promising sources of sustainable energy. ${ }^{17}$ However, the use of arable land and the clearing of carbon-rich forests for the cultivation of biofuel crops, such as corn or soy, could negatively affect the global food supply while actually increasing greenhouse gas emissions. ${ }^{18}$ Algae, on the other hand, do not require fertile soil and can be cultivated using wastewater, which is nutrient rich but generally prohibited in irrigation of food crops. In other words, producing biofuels from algae reduces competition for valuable arable land ${ }^{19,20}$ and allows us to utilize a 'waste' stream as a source for nutrients and water. ${ }^{21,22}$ Algae have a high photosynthetic efficiency that enables fast growth and further enhances their attractiveness as biofuel feedstocks. ${ }^{23}$

The Ames Research Center of the National Aeronautics and Space Administration (NASA) has undertaken the challenge of developing a system for feasible production of biofuels from algae. The Center has proposed a process that leverages FO to optimize growth and harvesting of microalgae while simultaneously treating wastewater. The system is known as OMEGA: Offshore Membrane Enclosure for Growing Algae. It could potentially circumvent several of the limitations of terrestrial algae cultivation with an elegant, low energy, and low impact engineering solution. ${ }^{19,20,22,23}$

OMEGAs consist of clear plastic enclosures with waterpermeable selective membranes incorporated into their surfaces
(Figure 2). The enclosures are filled with nutrient-rich municipal wastewater and seeded with algae which grow and produce lipids. ${ }^{24,25}$ The bags are deployed in high salinity aquatic environments, often oceans, where the water provides both infrastructural support through flotation and heat capacity for temperature regulation, ${ }^{24}$ and wave action provides mixing. OMEGAs utilize seawater as an unlimited and ever-present draw solution to dewater the algae broth, an otherwise energy-intensive and expensive process. ${ }^{24,25}$ The membranes integrated in the enclosures allow the passage of sunlight and the exchange of $\mathrm{CO}_{2} / \mathrm{O}_{2}$ to support algae photosynthesis. ${ }^{24}$ The dense selective layer of the membranes prevents or minimizes the escape of wastewater contaminants.

A significant advantage of OMEGAs is in algae biomass harvesting, a task that requires the culture broth to be dewatered. Efficient dehydration of the algal harvests is currently one of the main challenges of microalgae production, because of the low algal concentrations in the growth media. ${ }^{26}$ In OMEGAs, FO membranes retain algae and nutrients while facilitating removal of water from the bags through the osmotic pressure driving force provided by the higher salinity seawater. ${ }^{24}$ During a typical $10-20$ day algae incubation period, more than $75 \%$ of the water is removed from the algae culture by osmosis using abundant seawater as a draw solution. ${ }^{25}$ This partial dewatering greatly reduces the cost of the overall dehydration process. ${ }^{27}$

When the algae inside an OMEGA are ready for harvesting, the slurry is pumped out of the bags and sent to a processing facility that completes the dewatering process. The bags are then available for refilling with nutrient-rich wastewater to reinitiate the growth cycle. Biofouling often plagues systems that use membranes and wastewater or natural waters. However, several aspects of the OMEGA system suggest that biofouling will be less severe in this application. The relatively low water flux through the FO membrane will lead to low rates of fouling, and the lack of hydraulic pressure will ensure that any fouling that does occur is highly reversible. ${ }^{10}$

Despite the benefits of OMEGA systems, several challenges have been pointed out that merit further investigation. Though biofouling of the membrane's active layer inside the OMEGA may be minimal and reversible, fouling and scaling of the FO membrane support layer, which is in constant contact with seawater, may be more difficult to overcome. During the growth cycle, algae biofilms inside the OMEGA enclosure could decrease the rate of dewatering. ${ }^{28}$ In addition, membranes and other enclosure components need to be able to withstand pounding waves and cold temperatures. ${ }^{28-30}$

NASA envisions the OMEGAs producing enough fuel to meet U.S. aviation needs of 21 billion gallons a year, which would require 10 million acres of ocean, ${ }^{29}$ an area equal in size to Switzerland and twice as large as Massachusetts. This large area would be established by locally distributing the OMEGAs, or by creating a management structure in which fishermen franchised and monitored the systems. ${ }^{29} \mathrm{~A}$ demonstration plant planned for Santa Cruz, California will help determine if the OMEGA process can be feasibly implemented. ${ }^{22,30}$

\section{OSMOTIC AUGMENTATION OF WATER RESOURCES FOR AGRICULTURE}

The growing world population is increasingly stressing not only water and energy resources, but also food resources. With the amount of arable land unlikely to increase ${ }^{31}$ irrigation will be 

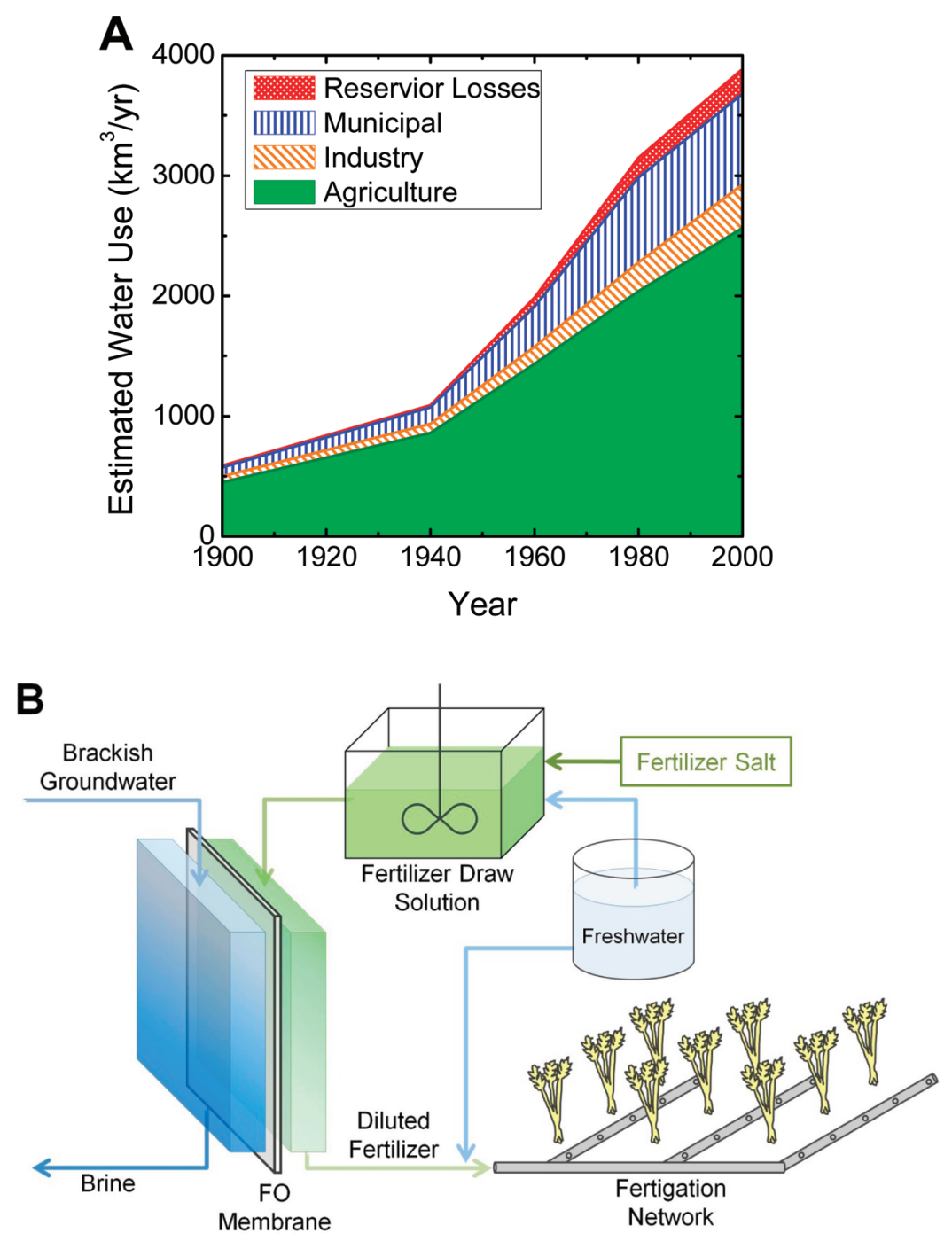

Figure 3. (A) Estimated water use over the past century. Agriculture currently accounts for $70 \%$ of global water withdrawals. (B) Schematic representation of forward osmosis (FO) application to increase the availability of water for irrigation through extraction of freshwater from brackish sources. The fertilizer is used to generate the concentrated draw solution, and brackish groundwater is used as the feed solution. The diluted fertilizer solution is subsequently applied to crops through a fertigation distribution network.

employed more extensively and effectively to meet the rising demand for food. ${ }^{32}$ Food production already requires large quantities of water. An estimated $70 \%$ of current global water withdrawals are for agricultural purposes ${ }^{33}$ (Figure 3A). Successfully feeding future generations will require sustainable technological improvements for irrigation and water management, 34,35 including innovative ways to increase the availability of water for agriculture. Here, FO holds promise to expand the water supply for irrigation by tapping an abundant, low value water sourcebrackish groundwater.

Water salinities above a crop's tolerance can stunt or prevent growth and diminish forage quality. ${ }^{36,37}$ Salt tolerance imposes a ceiling on the salinity of water that can be used and restricts irrigation sources to freshwater for most crops. Due to these restrictions and the limited availability of freshwater, brackish water is increasingly being desalinated for irrigation. ${ }^{38}$ In some regions where freshwater is scare, brackish water abounds. For example, in the U.S. state of New Mexico, approximately $75 \%$ of groundwater is too saline for most uses without pretreatment. ${ }^{39}$ Long-distance diversion of freshwater to such places is costly to society. FO can overcome the desalination energy hurdle to make replacing freshwater with locally available brackish water for irrigation more feasible, allowing both energy and freshwater to be conserved or used elsewhere. This can be achieved by the innovative use of concentrated fertilizer mixtures to extract water from brackish sources. ${ }^{40}$

In this FO application, a concentrated fertilizer solution is used as the draw solution while brackish water is employed as the feed stream. Water permeates the membrane, diluting the fertilizer solution. If needed, the solution can be mixed with freshwater to achieve the desired concentration of fertilizer. The fertilizer-bearing water is applied to crops through the irrigation system in a process called fertigation ${ }^{41}$ (Figure $3 \mathrm{~B}$ ).

FO-brackish water supplied fertigation could partially relieve agricultural demand for freshwater without incurring a large energy penalty, addressing both water and energy costs in food production. But first, a few challenges must be overcome. Concentrated brackish water must be used or disposed of properly, and brackish water resources must be managed responsibly to avoid subsidence and other problems associated with overdrawing from 
aquifers. Of paramount importance is the selection of a suitable fertilizer to generate the draw solution. On top of fulfilling the principle objective of crop fertilization, the draw salt also needs to be water-soluble, inexpensive, highly rejected by the FO membrane, and able to generate sufficient osmotic driving force for water permeation. ${ }^{42}$ A recent study estimated that $1 \mathrm{~kg}$ of fertilizer can extract 24-59 L of freshwater from a simulated brackish water of very high salinity ( $300 \mathrm{mM}$ sodium chloride ). ${ }^{43}$ More such studies are necessary to achieve a comprehensive evaluation of suitable fertilizer draw solutions. Additionally, the proper place of fertigation in a balanced portfolio of water management and allocation strategies used to support sustainable agriculture must be studied.

\section{OUTLOOK}

Unlike those currently at the focus of FO development, the FO applications described in this article avoid draw solution regeneration and thus can perform while using very little energy. These low-energy applications have the potential to enhance the energy efficiency of existing technologies, minimize pollution of aquatic and marine environments, utilize wastewater as a resource, or alleviate water shortages in agriculture. Specific limitations and research needs of each of the highlighted applications that must be overcome were indicated in the article.

At the core of the highlighted FO applications, and many more, is the FO membrane. Major progress has been made in the past few years in fabricating membranes for $\mathrm{FO}$, but more remains to be done to improve the performance of these membranes. Enhancing FO membrane water flux is of paramount importance, because this will reduce the required membrane surface area and thus the capital cost of FO systems. There is also a need to develop FO membranes with high solute rejection capabilities, not only to minimize the passage of contaminants from the feed stream into the draw solution, but also to minimize the reverse permeation of draw solutes into the feed stream. ${ }^{44}$

Unique to these resource-efficient FO applications is the exposure of the membranes to feed and draw solution streams with high fouling potential. Hence, there is a pressing need to develop membranes with low propensity for irreversible fouling in order to enable continuous operation without the need for costly pretreatment of the feed and draw solutions. Furthermore, membrane module configurations that maximize mixing for the continuous removal of foulants from the membrane surface need to be developed.

The FO applications described in this article, which are currently conceptual or at the early stages of development, have great potential to increase sustainability at the water-energy nexus as mature technologies. Additional research and development as well as process demonstration at the pilot-scale must be completed to permit successful implementation and commercialization. Adapting the advances of the past few decades in membrane technology and materials science to FO can put these technological achievements within our reach.

\section{AUTHOR INFORMATION}

\section{Corresponding Author}

*E-mail: menachem.elimelech@yale.edu.

\section{BIOGRAPHY}

Laura A. Hoover, Alberto Tiraferri, and Ngai Yin Yip are doctoral students researching membrane processes at the water-energy nexus in the Department of Chemical and Environmental Engineering at Yale University. William A. Phillip is an assistant professor in the Department of Chemical and Biomolecular Engineering at the University of Notre Dame. Prior to his present appointment, Dr. Phillip was a postdoctoral fellow in the Department of Chemical and Environmental Engineering at Yale University where he carried out research on membrane separation processes. Menachem Elimelech is the Roberto Goizueta Professor of Chemical and Environmental Engineering at Yale University and a World Class University Professor at Korea University in Seoul, Korea. His research focuses on membrane separation processes for sustainable production of water and power, environmental applications and implications of nanomaterials, and water and sanitation in developing countries.

\section{ACKNOWLEDGMENT}

We acknowledge the support of WaterCAMPWS, a Science and Technology Center of Advanced Materials for the Purification of Water with Systems under NSF grant CTS-0120978. We also acknowledge the EPA STAR Graduate Research Fellowship made to Laura Hoover, the Graduate Fellowship made by the Environment and Water Industrial Development Council of Singapore to Ngai Yin Yip, and the NWRI-AMTA Fellowship for membrane technology to Alberto Tiraferri.

\section{REFERENCES}

(1) McGinnis, R. L.; Elimelech, M. Energy requirements of ammonia-carbon dioxide forward osmosis desalination. Desalination 2007, 207 (1-3), 370-382.

(2) Cath, T. Y.; Childress, A. E.; Elimelech, M. Forward osmosis: Principles, applications, and recent developments. J. Membr. Sci. 2006, 281 (1-2), 70-87.

(3) Cath, T. Y.; Hancock, N. T.; Lundin, C. D.; Hoppe-Jones, C.; Drewes, J. E. A multi-barrier osmotic dilution process for simultaneous desalination and purification of impaired water. J. Membr. Sci. 2010, 362 (1-2), 417-426.

(4) National Research Council (U.S.). Committee on Advancing Desalination Technology. Desalination: A National Perspective; National Academies Press: Washington, DC, 2008; p xiv.

(5) Stoughton, R. W.; Lietzke, M. H. Calculation of some thermodynamic properties of sea salt solutions at elevated temperatures from data on $\mathrm{NaCl}$ solutions. J. Chem. Eng. Data 1965, 10 (3), 254-260.

(6) Elimelech, M.; Phillip, W. A. The future of seawater desalination: Energy, technology, and the environment. Science 2011, 333 (6043), 712-717.

(7) Semiat, R. Energy issues in desalination processes. Environ. Sci. Technol. 2008, 42 (22), 8193-8201.

(8) Bamaga, O. A.; Yokochi, A.; Zabara, B.; Babaqi, A. S. Hybrid $\mathrm{FO} / \mathrm{RO}$ desalination system: Preliminary assessment of osmotic energy recovery and designs of new FO membrane module configurations. Desalination 2011, 268 (1-3), 163-169.

(9) Spiegler, K. S.; El-Sayed, Y. M. The energetics of desalination processes. Desalination 2001, 134 (1-3), 109-128.

(10) Mi, B. X.; Elimelech, M. Organic fouling of forward osmosis membranes: Fouling reversibility and cleaning without chemical reagents. J. Membr. Sci. 2010, 348 (1-2), 337-345.

(11) Lattemann, S.; Höpner, T. Environmental impact and impact assessment of seawater desalination. Desalination 2008, 220 (1-3), $1-15$.

(12) Holloway, R. W.; Childress, A. E.; Dennett, K. E.; Cath, T. Y. Forward osmosis for concentration of anaerobic digester centrate. Water Res. 2007, 41 (17), 4005-4014.

(13) Ramon, G.; Agnon, Y.; Dosoretz, C. Dynamics of an osmotic backwash cycle. J. Membr. Sci. 2010, 364 (1-2), 157-166. 
(14) Fritzmann, C.; Löwenberg, J.; Wintgens, T.; Melin, T. State-of-theart of reverse osmosis desalination. Desalination 2007, 216 (1-3), 1-76.

(15) Qin, J.-J.; Oo, M. H.; Kekre, K. A.; Liberman, B. Development of novel backwash cleaning technique for reverse osmosis in reclamation of secondary effluent. J. Membr. Sci. 2010, 346 (1), 8-14.

(16) Sagiv, A.; Semiat, R. Backwash of RO spiral wound membranes. Desalination 2005, 179 (1-3), 1-9.

(17) Demirbas, A. Political, economic, and environmental impacts of biofuels: A review. Appl. Energy 2009, 86, S108-S117.

(18) Johansson, D. J. A.; Azar, C. A scenario based analysis of land competition between food and bioenergy production in the US. Clim. Change 2007, 82 (3-4), 267-291.

(19) Aaronson, S.; Dubinsky, Z. Mass-production of microalgae. Experientia 1982, 38 (1), 36-40.

(20) Pienkos, P. T. Darzins, A. The promise and challenges of microalgalderived biofuels. Biofuels, Bioprod. Biorefin. 2009, 3 (4), 431-440.

(21) Clarens, A. F.; Resurreccion, E. P.; White, M. A.; Colosi, L. M. Environmental life cycle comparison of algae to other bioenergy feedstocks. Environ. Sci. Technol. 2010, 44 (5), 1813-1819.

(22) Wiley, P. E.; Campbell, J. E.; McKuin, B. Production of biodiesel and biogas from algae: A review of process train options. Water Environ. Res. 2011, 83 (4), 326-338.

(23) Miao, X. L.; Wu, Q. Y. Biodiesel production from heterotrophic microalgal oil. Bioresour. Technol. 2006, 97 (6), 841-846.

(24) Trent, J. D.; Sherwin, J. G.; Delzeit, L. D.; Flynn, M. T. Embaye, T. N. Algae bioreactor using submerged enclosures with semi-permeable membranes. Patent 0216203, 2010.

(25) Trent, J. Win Sea Algae, International Workshop on Offshore Algae Cultivation, Maribo, Denmark, April 20-22, 2009.

(26) Decker, J., Blooming biofuel: How algae could provide the solution. Renewable Energy World Magazine June 22nd, 2009.

(27) AlgaeSystemsLLC OMEGA. http://algaesystems.com/technology/omega/ (accessed)

(28) Zou, S.; Gu, Y. S.; Xiao, D. Z.; Tang, C. Y.Y. The role of physical and chemical parameters on forward osmosis membrane fouling during algae separation. J. Membr. Sci. 2011, 366 (1-2), 356-362.

(29) Howell, K., NASA bags algae, wastewater in bid for aviation fuel. The New York Times May 12th, 2009.

(30) NASA-NAVY. OMEGA: A Strategic Planning Discussion; NASA-NAVY: Norfolk, VA, March 25, 2010.

(31) Fedoroff, N. V.; Battisti, D. S.; Beachy, R. N.; Cooper, P. J. M.; Fischhoff, D. A.; Hodges, C. N.; Knauf, V. C.; Lobell, D.; Mazur, B. J.; Molden, D.; Reynolds, M. P.; Ronald, P. C.; Rosegrant, M. W.; Sanchez, P. A.; Vonshak, A.; Zhu, J. K. Radically rethinking agriculture for the 21 st century. Science 2010, 327 (5967), 833-834.

(32) Plusquellec, $\mathrm{H}$. Is the daunting challenge of irrigation achievable? Irrig. Drain. 2002, 51 (3), 185-198.

(33) FAO AQUASTAT database. http://www.fao.org/nr/aquastat (accessed).

(34) Falkenmark, M.; Rockstrom, J.; Karlberg, L. Present and future water requirements for feeding humanity. Food Secur. 2009, 1 (1), 59-69.

(35) Tilman, D. Global environmental impacts of agricultural expansion: The need for sustainable and efficient practices. Proc. Natl. Acad. Sci. U.S.A. 1999, 96 (11), 5995-6000.

(36) Maas, E. V.; Hoffman, G. J. Crop salt tolerance-Current assessment. J. Irrig. Drain. Div., Am. Soc. Civ. Eng. 1977, 103 (IR2), $115-134$.

(37) Flowers, T. J. Improving crop salt tolerance. J. Exp. Bot. 2004, 55 (396), 307-319.

(38) Yermiyahu, U.; Tal, A.; Ben-Gal, A.; Bar-Tal, A.; Tarchitzky, J.; Lahav, O. Environmental science-Rethinking desalinated water quality and agriculture. Science 2007, 318 (5852), 920-921.

(39) Reynolds, S. Twenty-Fifth Biennial Report of the State Engineer of New Mexico for the 49th and 50th Fiscal Years July 1, 1960 to June 30, 1962; The Valliant Company: Albuquerque, NM, 1962, p 193.

(40) Moody, C. D.; Kessler, J. O. Forward osmosis extractors. Desalination 1976, 18 (3), 283-295.
(41) Bar-Yosef, B. Advances in fertigation. Adv. Agron. 1999, 65, $1-77$.

(42) Achilli, A.; Cath, T. Y.; Childress, A. E. Selection of inorganicbased draw solutions for forward osmosis applications. J. Membr. Sci. 2010, 364 (1-2), 233-241.

(43) Phuntsho, S.; Shon, H. K.; Hong, S.; Lee, S.; Vigneswaran, S. A novel low energy fertilizer driven forward osmosis desalination for direct fertigation: Evaluating the performance of fertilizer draw solutions. J. Membr. Sci. 2011, 375 (1-2), 172-181.

(44) Phillip, W. A.; Yong, J. S.; Elimelech, M. Reverse draw solute permeation in forward osmosis: Modeling and experiments. Environ. Sci. Technol. 2010, 44 (13), 5170-5176. 